\title{
STATURE OF SCOTSMEN AGED 18 TO 40 YEARS IN 1941
}

BY

\author{
E. M. B. CLEMENTS and KATHLEEN G. PICKETT \\ Department of Anatomy, University of Birmingham
}

Between 1939 and 1946, over 7 million men were examined by the medical boards of the Ministry of Labour and National Service out of a possible population of about 10 million. The object of the examination was to separate the fit from the unfit for military service. The records give information about both these classes, and provide a mass of data-which could hardly have been collected by normal methods of research-about the relationship between certain body measurements, occupation, age, place of birth, and medical grade.

These records have been made available to us, and are being used to estimate the distribution of stature, weight, and chest circumference in the population, and to define such variations in these measurements as can be related to age, domicile, and occupation. Knowledge about the way stature and weight vary in the population is useful in dealing with a number of practical problems, such as the assessment of nutritional status, and the standardization of the dimensions of equipment and clothing. A preliminary study has been made of the data for Scotland, and the findings for stature are reported here.

\section{MATERIAL}

Measurements of stature, weight, and chest circumference were recorded with certain social data in the course of the National Service Medical examination and these records form the basis of the analysis. Several considerations indicate that they are sufficiently reliable for the purpose of the present study. For instance, the pattern of differences between the means in various sub-classifications of the records of each Medical Board is similar in our sample.

Because of the war-time policy of call-up by age group, and of the reservation in civilian service of certain occupations, some age groups are better represented than others in the records, and certain occupations appear less frequently than would be expected from their proportions in the census. There is no reason to suppose, however, that those belonging to any occupation or age group who were called for examination were in any way selected on physical grounds. It may, therefore, be taken that the data abstracted from the records refer to a random sample within occupations and age groups, but that the numbers in the groups are not in proportion to their occurrence in civilian life.
The survey has been based on records taken in 1941, a period when the call-up was very wide and likely to cover the greatest number of occupations and age groups, and it appears that the records of this year cover approximately half the age range of the working population.

Blind and known mentally-defective persons were exempt from registration under the National Service Acts. Obvious cripples and men who were unable to attend for examination without escort were not examined, and a few subjects who were obviously unfit were not completely examined and have incomplete records. Such persons, who cannot be regarded as full members of the working population, have been excluded from this analysis.

\section{Treatment of Data}

The results of previous surveys of the stature of adult males in England and Scotland suggest that about 200 records constitute the smallest sample from each board which will permit of the necessary sub-classifications by age, social class, and place of origin. It appeared from the records that some medical boards dealt with the candidates systematically in different groups; for example, all the candidates at one session might occasionally be either volunteers or conscripts; or follow the same occupation; or have a similar medical history.

The records are bound in volumes. Those made available to us covered the period January 1, 1941, to March 31, 1941, with the exception of a few boards which dealt with sparsely populated areas. The records were sampled in the following way:

$\begin{array}{ccc}\begin{array}{c}\text { No. of } \\ \text { Volumes in } \\ \text { Period }\end{array} & \begin{array}{c}\text { Sampling } \\ \text { Fraction }\end{array} & \begin{array}{c}\text { No. of } \\ \text { Volumes } \\ \text { Selected }\end{array} \\ 20-25 & 1 / 4 & 5-6 \\ 15-20 & 1 / 3 & 5-6 \\ 10-15 & 1 / 2 & 5-7 \\ 7-10 & 2 / 3 & 5-6 \\ 5-7 & 1 / 1 & 5-7\end{array}$

Of the records of the boards which dealt with sparsely populated areas, five consecutive volumes were taken, starting with January 1, 1941, regardless of the period covered.

The records contained in the volumes were sampled systematically, by taking every third entry of a first examination of men born in England, Wales, or Scotland. This procedure gave a sample of approximately 200 records for each medical board. 
To ensure that each subject contributed only one entry in the present analysis only first examinations were abstracted.

\section{INFORMATION ABSTRACTED}

Town in which Board was Held.-This represents the area of the subjects' residence at the time of examination. These towns have been grouped into regions according to the Registrar-General's geographical classification.

Age in Years.-This was calculated from the date of birth to the date of examination.

Place of Birth.-Coded into county and administrative area, from the Registrar-General's Index of Place Names. The Index of Scottish Place Names appears as an appendix to Volume 2 of the Report on the 1931 Census of Scotland.

Stated Occupation.-For the sake of uniformity, because there is no satisfactory alternative, and because it is the basis of the census, occupations have been coded according to the 1950 classification of the General Register Office. Related occupations are grouped by the Registrar-General into "Occupation Orders". Occupations are also grouped into five categories called by the Registrar-General "Social Classes". The same occupation order may relate to two or more social classes. We have retained these terms, and (with the single exception of the transfer of students to Class 2) have employed the Registrar-General's classification throughout the present analysis.

The records of the separate medical boards for Class 1 are too few for independent analysis, and they have been combined with Class 2 to form a composite class referred to as "Class $1 / 2$ " in the main part of the analysis. These two classes can be examined separately after the samples from the medical boards have been combined into a "national" sample (see below).

Anthropometric Data.-Measurements of body weight, stature, and chest circumference have been copied as recorded, converting from fractions to the first place of decimals. To avoid the introduction of any systematic error, one-quarter was taken down to $0 \cdot 2$, and three-quarters up to $0 \cdot 8$.
The medical boards measured height in inches and fractions of an inch, with the subjects standing erect against a height-measuring standard, without shoes. Apparently there were no directions regulating the precise posture of the head when the men were measured.

A frequency distribution of stature showed that most measurements were made to the nearest inch and half inch, with some at the intermediate quarters.

Previous studies by Davenport, Steggerda, and Drager (1934) have shown that "observer error" is a relatively insignificant factor in the measurement of stature. Any differences in the technique used by various boards when making the measurements will increase the variance between the boards and will be included in the geographical factor.

Medical Grade.-In certain circumstances the grading was deferred, either for a specialist's examination or because of a proposed further examination by the board at a later date. These have been assigned to a group referred to below as "unclassified". Medical grades 1 and 2 have been classed as "Fit", and 3 and 4 as "Unfit".

The information abstracted was coded and punched on to Hollerith cards from which the statistical analysis has been made. The necessary sums of squares and cross products have been obtained by the technique of progressive digiting (Eckert, 1941).

Most of the tests of significance have been made by an analysis of variance. Because its effect on adult stature is so small, age has not been standardized in the tests of geographical variation. For the more detailed analyses of the occupational groups, age has been standardized by making the tests of significance in the form of a covariance analysis with age.

Differences between means in which $P \leqq 0.01$ have been regarded as statistically significant, except when examining the geographical factor, where the 5 per cent. level $(P=0.05)$ has been used.

\section{Analysis of Data}

The data were obtained from seventeen medical boards, grouped for the analysis into the regions used by the Registrar-General for Scotland.

TABLE J

AGE DISTRIBUTION OF THE SAMPLE

\begin{tabular}{l|c|c|c|c|c|c|c|c|c|c|c|c|c|c|}
\hline Age & 17 & 18 & 19 & $20-24$ & $25-29$ & $30-34$ & $35-39$ & $40-42$ & All \\
\hline Number .. & 4 & 124 & 944 & 736 & 445 & 508 & 887 & 44 & 3,692 \\
\hline Percentage & $0 \cdot 11$ & $3 \cdot 36$ & $25 \cdot 57$ & $19 \cdot 93$ & $12 \cdot 05$ & $13 \cdot 76$ & $24 \cdot 02$ & $1 \cdot 19$ & $99 \cdot 99$ \\
\hline
\end{tabular}


TABLE II

MEAN STATURE FOR REGIONS BY AGE GROUPS

\begin{tabular}{|c|c|c|c|c|c|}
\hline \multirow{2}{*}{ Region } & \multicolumn{4}{|c|}{ Age Group } & \multirow{2}{*}{ All Ages } \\
\hline & $17-19$ & $20-29$ & $30-39$ & \multirow{2}{*}{$\frac{40-42}{(1)}$} & \\
\hline Southern & $67 \cdot 14 \pm 0 \cdot 24$ & $67 \cdot 29 \pm 0 \cdot 21 \quad(140)$ & $66.45 \pm 0.24$ & & $66.96 \pm 0.13 \quad(409)$ \\
\hline West Central & $66 \cdot 73 \pm 0 \cdot 14$ & $66 \cdot 87 \pm 0 \cdot 14$ & $66 \cdot 30 \pm 0 \cdot 15$ & $66.59 \pm 0.56$ & $66.65 \pm 0.08(1,103)$ \\
\hline East Central & $66.91 \pm 0.15 \quad$ (258) & $67 \cdot 05 \pm 0 \cdot 14$ & $66 \cdot 40 \pm 0 \cdot 14$ & - & $66.78 \pm 0.08 \quad(895)$ \\
\hline Northern & $67 \cdot 17 \pm 0 \cdot 14$ & $66.96 \pm 0.14$ & $66 \cdot 78 \pm 0 \cdot 11$ & $67.47 \pm 0.52$ & $66.94 \pm 0.07(1,285)$ \\
\hline Total & $66.96 \div 0.08(1,072)$ & $66.99 \pm 0.08(1,181)$ & $66 \cdot 55 \pm 0.07(1,395)$ & $67 \cdot 22 \pm 0 \cdot 39$ & $66.82 \pm 0.04(3,692)$ \\
\hline
\end{tabular}

The means are given in inches, and the numbers in each sample in brackets

The sampling of the volumes gave a total of 3,812 records, of which $120(3 \cdot 15$ per cent. of the total and mainly all with gross disability) were rejected because of incomplete information. This left a sample of 3,692 for analysis.

Table I shows the distribution of the 3,692 complete records by age group. Nearly 60 per cent. fall between the ages of 19 and 29 .

The distribution of the whole sample by "Social Class" is shown in Table V. The relative proportions of the classes were found to differ considerably from one area to another.

Stature.-This was examined first because it is of great practical importance, and because many sub-dimensions of body length (e.g. leg length) which affect the dimensions of equipment (e.g. chairs) are closely correlated with it. As was anticipated it proved to have a normal distribution, thus enabling statistical tests of significance to be applied with confidence.

The mean statures for the regions of Scotland are set out in Table II. The mean for the whole sample of 3,692 records is $66 \cdot 82^{\prime \prime} \pm 0.04$, which is significantly less than the mean of $67.0^{\prime \prime} \pm 0.03$ for the 9,623 (native) Scotsmen aged 20 measured in 1939 (Martin, 1949). That this is probably due to differences in the age range of the samples, is indicated by the fact that the mean of our 19-year-old sample $\left(66.99^{\prime \prime} \pm 0 \cdot 09\right)$ is practically identical with the 1939 mean.

The data presented in Table II are made up of records from all social classes, and as already observed the proportions vary from area to area. The data are broadly grouped on a regional basis, but the areas are large and may contain limited sub-areas showing significant variations in stature. These may be grouped and termed "geographical factors". These data are therefore regarded as heterogeneous, and the analysis has been arranged so that these factors may be examined separately, and the detailed analysis made on homogeneous samples.
The mean statures for each medical board and each different region have been compared only within the same social class. The mean stature for each medical board within a region was obtained and the significance of the differences between means was tested by an analysis of variance. This method provided information that was sufficiently accurate for the present purpose. The slight gain in accuracy that could be obtained from more rigorous and complex statistical techniques would not justify the additional labour involved.

The distribution of stature was regarded as homogeneous, and the area of agreement termed a "homogeneous region" if there was no significant difference between the mean statures of the samples of the same social class from the various medical boards. When a significant difference was found, the sample for the medical board showing the greatest discrepancy when compared with the mean for the whole region was removed from the combination of boards for separate consideration. The regional total and variance were adjusted accordingly and the figures re-tested for homogeneity. If they proved to be homogeneous, this combination of boards was classified as an "adjusted region". If not, the process was repeated until one was defined. Thus 68 samples relating to four social classes from seventeen medical boards in the four regions have been examined. The homogeneous means for the social classes are presented in Table III (overleaf).

The means for the homogeneous and adjusted regions proved to be homogeneous for each social class, and the regional data have been combined into what is termed a "national sample" for each social class. These are the totals of the classes given in Table III. The national sample for each social class applies to the whole of Scotland (less the heterogeneous areas segregated as "separate" areas), and defines an area over which the stature of the class is statistically homogeneous. In this way, geographical variation has been eliminated 
TABLE III

MEAN STATURE RELATED TO SOCIAL CLASS AND GEOGRAPHICAL REGION

\begin{tabular}{|c|c|c|c|c|c|}
\hline Region & Class 1 & Class 2 & Class 3 & Class 4 & Class 5 \\
\hline $\begin{array}{l}\text { Southern } \\
\text { West Central } \\
\text { East Central } \\
\text { Northern }\end{array}$ & $\begin{array}{l}68 \cdot 42^{*} \pm \\
67 \cdot 55 \\
68 \cdot 03 \pm \\
67.83\end{array}$ & $\begin{array}{l}.46(28) \\
.25(105) \\
.30(77) \\
.20(129)\end{array}$ & $\begin{array}{l}66.97 \pm \overline{0.12}(542) \\
66 \cdot 86 \pm 0 \cdot 11(455) \\
66 \cdot 75 \pm 0.12(464)\end{array}$ & $\begin{array}{l}66 \cdot 98 \pm 0.31(85) \\
66 \cdot 17 \pm 0.19(188) \\
66 \cdot 27 \pm 0.22(136) \\
66.52 \pm 0.20(163)\end{array}$ & $\begin{array}{l}66 \cdot 32 \pm \overline{0} \cdot 18(174) \\
66.51 \pm 0.17(227) \\
66.43 \pm 0.15(319)\end{array}$ \\
\hline Totalt $\quad(a)$ & $68.93 \pm 0.37$ & $67 \cdot 70 \pm 0 \cdot 14(301)$ & $66.87 \pm 0.07(1,461)$ & $66 \cdot 42 \pm 0.11(572)$ & $66 \cdot 44 \pm 0 \cdot 10(720)$ \\
\hline $\begin{array}{l}\text { Means re- } \\
\text { corded in } \\
1883 \ddagger \quad(\text { b })\end{array}$ & $69 \cdot 14 \pm 0 \cdot 22$ & $67 \cdot 95 \pm 0 \cdot 18$ & $66 \cdot 61 \pm 0 \cdot 13$ & 一 & 一 \\
\hline$(a)-(b)$ & $-0.79 \pm 0.43$ & $-0.25 \pm 0.23$ & $0.26 \pm 0.15$ & - & - \\
\hline
\end{tabular}

* In the analyses Social Classes 1 and 2 are combined as Class $1 / 2$, mean $67 \cdot 84 \pm 0 \cdot 13$ (339).

t The mean of the combined Social Classes ("pooled national sample") $=66 \cdot 79 \pm 0.05$ (3092).

$\ddagger$ Data for 1883 are from British Association Report (1884).

The standard errors of the means have been derived from the probable errors given by Goring (1913).

and large pooled samples built up for the detailed analysis of occupational differences.

The national samples of all the social classes have been combined into the "pooled national sample" which represents the weighted mean stature of Scotland (excluding the heterogeneous areas) taking account of the relative number in each class. This mean is $66 \cdot 79^{\prime \prime} \pm 0.05(3,092)$. Ten heterogeneous boards were found, and of these, three were in Social Class 3, two in Class 4, and five in Class 5. Together they make up 600 records and represent the difference between the total numbers in Tables II and III. These separate areas have been examined in the section on geographical factors, and apart from the main sample.

Geographical Factors.-It is apparent from Table II that there is a tendency for the mean stature of the West Central Region to be the shortest in each age-group, although the actual differences are small in each case. The more detailed examination confirms that the geographical variation is slight within the social classes. Significant variation is limited to two small areas which show relatively large differences in mean stature when compared with the rest of the region.

The means of the samples from the north of the mainland for Social Classes 3 and 4, and from the Shetland Islands for Social Classes 4 and 5, are about one inch above the means of the national samples for these classes. These differences are significant. The means of the samples from Paisley and Glasgow for Social Class 5 are about one inch below the mean of the national sample for this class. This difference is also significant.

The means of the samples for Social Classes 3 and 5 of the two boards of the Southern Region differ significantly, but little importance is attached to this difference, which may be due to a high proportion of newcomers into the region. The samples are not included in the national samples.

These records have been analysed, although most of the samples are too small to allow of detailed examination.

There is no significant difference between the stature means for the different social classes in Lerwick $(F=2 \cdot 5, d . f .3)$. For Wick, there is a significant difference $(F=4 \cdot 42$, d.f. 3$)$, almost certainly due to the low mean stature of Social Class 5. When the samples for Social Classes 3, 4, and 5 for Lerwick and Wick are pooled, the mean of the combined sample is $67.48^{\prime \prime} \pm 0.04$, and is not significantly different from the mean of Class $1 / 2$ of the Northern Region (' $t$ ' $=1 \cdot 42$ ). The mean statures of Classes 3, 4, and 5 are not only similar to those generally found in Class $1 / 2$ but the distribution of stature is homogeneous in the area.

With the exception of the Southern Region, there is no significant difference between the mean stature of the samples of the "separate" areas for the same region and social class. These samples, with the exception of those from the Southern Region, have therefore been pooled, and classified by occupation into the occupation orders. No significant difference between the means was found when the means and variance of stature were computed for these sub-samples. It is apparent that the significantly different means statures of these areas cannot be accounted for by any one occupational group.

The mean stature for Social Class $1 / 2$ is the same in all regions.

Martin's analysis (1949) of the Scottish data for 1939 was based on a regional classification different from that of the Registrar-General of Scotland, and revealed a difference of $1 \cdot 1^{\prime \prime}$ between the means 
of the tallest and shortest region. It also showed that the Highland area (approximately our Northern Region) had the highest mean stature, and the Glasgow and Paisley areas the lowest. Tocher (1924) gave the stature for seven regions of Scotland derived from height measurements of Scottish soldiers in 1916. These may have been subject to some selection, as some minimum standard of stature may have been required on recruitment. Nevertheless his figures also suggest that the tallest samples came from the North and the shortest from the lower Clyde valley.

A Report presented by the Anthropometric Committee of the British Association in 1883 (published in 1884) gave the average stature for various regions of Scotland, with the number in each sample. The mean of $68 \cdot 71^{\prime \prime}$ for the whole sample of 1,369 records is remarkably high, when compared with the 1941 figure of $66 \cdot 82^{\prime \prime}$. It is even significantly greater (by $0.9^{\prime \prime}$ ) than the 1941 figure for Class $1 / 2$. Table $V$ shows that these earlier data paid little attention to occupational classification, and that a high proportion of the subjects measured were professional men. A re-assessment of these data indicates that only the two tallest samples (from the areas of (i) Kirkcudbright, Ayr, and Wigtown, and (ii) Edinburgh, Linlithgow, Haddington, and Berwick) differ significantly from samples from the other geographical samples studied, and that all the variation found between the other samples may be ascribed to random errors of sampling.

The likelihood is that we are dealing here with genetic factors, possibly due to migration and selection.

Stature related to Social Class.-The main variation in adult stature appears to be associated with social class. A test of significance comparing the means of the national samples of the classes (Table III) shows that the differences are statistically significant $(F=26 \cdot 9$, d.f. 3 , and 3,087$)$. The tallest mean is found in Class $1 / 2$, followed by that of Class 3, and then those of Classes 4 and 5 come together. The difference between the means of Classes 4 and 5 is not significant. There is a significant difference of about one inch between the constituent classes of Class $1 / 2(t=3 \cdot 1)$. The difference of one inch between Classes $1 / 2$ and Class 3 is also significant $(t=6 \cdot 52)$. The difference between Classes 3 and 4, and between Classes 3 and 5 (each $\left.\frac{1}{2}^{\prime \prime}\right)$ are significant $(t=3 \cdot 5$ and $3 \cdot 6$ respectively).

Differences between the mean statures of the different social classes which are also apparent in the data of 1883 are indicated in Table III.
The present analysis shows that stature in Scotland varies more between socio-economic groups than it does between geographical regions. The implication of this fact, which also applies to other countries (e.g. Lundborg and Linders, 1926), can only be that different occupations attract men of different height, or that men in different sections of the community are attracted to different kinds of occupation. The second, which is the commonsense and more likely alternative, is supported by the observation that the highest mean stature is found in Social Class I, from which men in the professions, as opposed to other occupations, are drawn.

Stature related to Age.-The British Association Anthropometric Committee of 1883 wrote:

... it is probable that little actual growth takes place after the age of 21 years, and that it entirely ceases by the 25th year. Full stature is attained earlier in the wellfed and most favoured class than in the ill-fed and least favoured classes of the community.

This observation has since been amply confirmed; Morant (1950) showed that the mean stature of present-day regular recruits into the Royal Air Force does not increase after about 20 years, whereas the mean stature increased until 24 years of age in recruits into the Army in 1913, and until 26 years in recruits in 1880 . Kemsley (1950) found that in 1943 the mean stature of a composite sample of English and Scottish industrial workers did not increase after 22 years of age.

The data dealt with here indicate that Scotsmen of all social classes reach adult stature by their 19 th year. The data analysed by the British Association Anthropometric Committee in 1883 showed that individuals corresponding to Social Class $1 / 2$ then reached mature stature at about 18 to 19 years, and those corresponding to our Social Classes 3, 4, and 5 , reached it at about 22 years. Thus, while there has been no change in the mean stature at maturity over the past 70years, the average age at which full stature has been reached by men who fall into the non-professional classes has become increasingly less. Furthermore, the growth rates of the different classes no longer differ after 18 years of age.

Table II shows a tendency for the mean stature to be less in the over-30 age group than in the over- 20 age group. The over- 40 age group does not apparently follow this trend, but here the samples are very small. The trend has been examined in detail, and such slight changes in adult stature as occur after the age of 18 years may adequately be described by a linear regression.* The regression

\footnotetext{
*Linear regression equations fit the data well, and curved regressions of the form $y=a+b x+c x^{2}$ (where $a$ is a constant, $b$ and $c$ are coefficients, $x$ is age in years, and $y$ is stature) do not improve the fit significantly.
} 
TABLE IV

REGRESSION COEFFICIENTS OF STATURE ON AGE (IN INCHES PER YEAR) FOR AGE RANGE 18-40 YEARS

\begin{tabular}{|c|c|c|c|c|c|c|c|c|c|c|}
\hline \multirow{2}{*}{ Age Group } & \multicolumn{2}{|c|}{ Class 1 and 2} & \multicolumn{2}{|c|}{ Class 3} & \multicolumn{2}{|c|}{ Class 4} & \multicolumn{2}{|c|}{ Class 5} & \multicolumn{2}{|r|}{ Pooled } \\
\hline & $n$ & $b$ & $n$ & $b$ & $n$ & $b$ & $n$ & $b$ & $n$ & $b$ and S.E. \\
\hline $\begin{array}{l}17-19 \\
20-29 \\
30-39 \\
40-42\end{array}$ & $\begin{array}{r}81 \\
100 \\
153 \\
5\end{array}$ & $\begin{array}{r}0.917 \\
-0.028 \\
-0.007 \\
-\end{array}$ & $\begin{array}{r}488 \\
545 \\
426 \\
2\end{array}$ & $\begin{array}{r}0.481 \\
-0.054 \\
-0.087 \\
-\end{array}$ & $\begin{array}{r}158 \\
194 \\
215 \\
5\end{array}$ & $\begin{array}{c}-0.281 \\
-0.013 \\
-0.074 \\
-\end{array}$ & $\begin{array}{r}146 \\
173 \\
385 \\
16\end{array}$ & $\begin{array}{l}-0.656 \\
-0.055 \\
-0.115 \\
-1.151\end{array}$ & 873 & $0.254 \pm 0.278$ \\
\hline Average & 339 & -0.017 & 1461 & -0.061 & 572 & -0.034 & 720 & -0.087 & 3092 & $-0.032 \pm 0.007$ \\
\hline $\begin{array}{l}\text { Deviation from } \\
\text { average regressions }\end{array}$ & \multicolumn{2}{|c|}{$1949 \cdot 8797$} & \multicolumn{2}{|c|}{$9530 \cdot 5026$} & \multicolumn{2}{|c|}{$3959 \cdot 6053$} & \multicolumn{2}{|c|}{$4775 \cdot 2226$} & \multicolumn{2}{|r|}{$20336 \cdot 2653$} \\
\hline $\begin{array}{l}\text { Deviation from indi- } \\
\text { vidual regressions }\end{array}$ & \multicolumn{2}{|c|}{$1944 \cdot 0544$} & \multicolumn{2}{|c|}{$9513 \cdot 2733$} & \multicolumn{2}{|c|}{$3956 \cdot 5306$} & \multicolumn{2}{|c|}{$4761 \cdot 2221$} & \multicolumn{2}{|r|}{$20307 \cdot 1936$} \\
\hline$F$ & \multicolumn{2}{|c|}{$<1$} & \multicolumn{2}{|c|}{$<1$} & \multicolumn{2}{|c|}{$<1$} & \multicolumn{2}{|c|}{$<1$} & \multicolumn{2}{|r|}{$1 \cdot 47$} \\
\hline
\end{tabular}

Average regression coefficient of stature and age over age range 18-40 years for all social classes $-0 \cdot 032 \pm 0 \cdot 007$.

coefficient of height on age for our pooled sample from 18 to 40 years is $-0.032 \pm 0.007$. The negative value of ' $b$ ' implies that height begins to decline once adult stature is attained, an observation which corroborates Morant's finding.

In Table III is given the mean stature derived from all the data for age groups covering the period from 18 to 42 years. The mean statures of the first two groups are of critical importance, because they cover the period in which the change occurs from annual increments (growth as usually understood) to the adult state.

Regression coefficients for height on age have been computed separately for individuals under 19; for the age group 20-29; and for the age group 30-39, and corresponding regression for the age group 40-42 of Social Class 5 was also calculated (Table IV). None of the coefficients for each social class differ significantly from the coefficient relating stature to age for the whole age-range of the class in question.

The regression coefficients of stature on age for each of the social classes of the first age group (up to and including the 19-year-olds) do not differ significantly.

A mean regression coefficient, computed for all the data by pooling all the social class groups, does not differ significantly from the overall mean regression for each social class.

Stature in 1883 and in 1941.-Mean statures of the different social classes in $\mathbf{1 8 8 3}$ are given in Table III. The differences are very similar to those found in 1941; differences between means of the two surveys for the same class are not significant.

The mean statures for 1883 and 1941 cannot be compared area by area, partly because only a few samples have the same geographical boundaries in both surveys, and partly because average statures by birthplace in the 1883 report were not standardized for social class. Table $\mathrm{V}$ shows that distribution by social class is quite different in the two samples, but a comparison can be made in the case of the Shetland Islands, where no significant differences were found between the mean statures of the four social classes of 1941 (mean 67.48" $\pm 0 \cdot 20$ ). The mean stature for the Shetlands for all classes in 1883 was $67 \cdot 92^{\prime \prime}(n=108)$. Assuming the same variance for the two sets of data, the difference between the means is not statistically significant.

TABLE V

COMPOSITION BY SOCIAL CLASS OF THE SAMPLES OF 1941 AND 1883

\begin{tabular}{|c|c|c|c|c|}
\hline \multirow{2}{*}{$\begin{array}{c}\text { Social } \\
\text { Class }\end{array}$} & \multicolumn{2}{|c|}{1941 Sample } & \multicolumn{2}{|c|}{$1883^{*}$ Sample } \\
\hline & No. & Percentage & No. & Percentage \\
\hline $\begin{array}{l}1 \\
2 \\
3\end{array}$ & $\begin{array}{r}38 \\
301 \\
1,740\end{array}$ & $\begin{array}{r}1 \cdot 0 \\
8 \cdot 2 \\
47 \cdot 1\end{array}$ & $\begin{array}{r}10,739 \\
5,472 \\
12,636\end{array}$ & $\begin{array}{l}28 \cdot 6 \\
14 \cdot 6 \\
33 \cdot 6\end{array}$ \\
\hline $\begin{array}{l}4 \\
5\end{array}$ & $\begin{array}{l}645 \\
968\end{array}$ & $\begin{array}{l}17 \cdot 5 \\
26 \cdot 2\end{array}$ & 8,727 & $23 \cdot 2$ \\
\hline Total & 3,692 & $100 \cdot 0$ & 37,574 & $100 \cdot 0$ \\
\hline
\end{tabular}

Stature related to Occupation.-Each "social class" may relate to a number of "occupational orders". An analysis has been made of the national samples of the social classes in which the differences between the means of the occupational orders were tested for significance by a covariance analysis, thereby taking age differences into account. It showed that there were no significant differences between the mean statures of the occupational orders at either the 1 or 5 per cent. levels of probability.

Cathcart, Hughes, and Chalmers (1935) have given the mean statures for certain occupational groups in Glasgow, but they are not sub-classified by social class. Kemsley (1950) has given the mean 
TABLE V]

MEAN STATURE AND DISTRIBUTION OF THE FIT AND THE UNFIT, BY SOCIAL CLASS

\begin{tabular}{|c|c|c|c|c|c|}
\hline \multirow{3}{*}{$\begin{array}{c}\text { Class } \\
1 / 2\end{array}$} & \multicolumn{3}{|c|}{ Fitness } & \multirow{3}{*}{$\begin{array}{c}\text { Test of Significance } \\
<1\end{array}$} & \multirow{3}{*}{$\frac{\text { Percentage Fit }}{77 \cdot 9}$} \\
\hline & Fit & Unfit & Not Known & & \\
\hline & $67 \cdot 88 \quad(264)$ & $67 \cdot 82$ & $68 \cdot 22$ & & \\
\hline 3 & $66 \cdot 83(1,185)$ & $66 \cdot 73 \quad(240)$ & $67 \cdot 41$ & $1 \cdot 1$ & $81 \cdot 1$ \\
\hline 4 & $66 \cdot 45 \quad(445)$ & $66 \cdot 32 \quad(112)$ & $66 \cdot 28$ & $<1$ & $77 \cdot 8$ \\
\hline 5 & $66 \cdot 54 \quad(517)$ & $66.46 \quad(180)$ & $67 \cdot 16$ & $<1$ & $71 \cdot 8$ \\
\hline Total & $66 \cdot 81(2,411)$ & $66.69 \quad(598)$ & $67 \cdot 23$ & $1 \cdot 63$ & $78 \cdot 0$ \\
\hline
\end{tabular}

statures of samples of Scottish miners $\left(66 \cdot 0^{\prime \prime}\right)$ and of Scottish workers (large firms 66.2", small 65 $7^{\prime \prime}$ ). Both these sets of figures refer to a standardized age of about 37 years and they should be increased slightly, by say $0 \cdot 1^{\prime \prime}$, to make them comparable to the means in this survey. Kemsley's mean statures are almost identical to ours of $66.05^{\prime \prime}$ for miners and $66.42 "$ for Social Class 5. The mean statures found by Cathcart and others (1935), with the exception of the clerical order, are less than those found in this survey.

Nine of the larger occupational orders, including metal, transport, and commercial workers, were examined, taking each social class separately. The differences between the mean statures of the samples of the occupations within the social classes were examined by a covariance analysis, taking age differences into account. Within the orders examined none of the differences between the stature means of the various occupations were significant at the 1 per cent. level and only one (the professional order) was significant at the 5 per cent. level of probability.

Stature related to Fitness.-The mean stature of the unfit within each social class is not significantly different from that of the fit or of those "not graded", nor does any difference emerge when all the classes are combined (Table VI). A $\chi^{2}$ test showed that there are significantly more fit men in Social Class 3 and fewer in Social Class 5 than in the average of the whole population $\left(\chi^{2}=24 \cdot 7\right.$, d.f. 6$)$.

The stature of men whose records had to be rejected because of incompleteness (most of whom were unfit for service) did not differ from that of the able-bodied.

Stature related to Classification as Volunteers and Conscripts.-The mean stature of conscripts within each social class is not significantly different from that of Volunteers (Table VII), nor did any difference emerge when the social classes were pooled.
TABLE VII

MEAN STATURE AND DISTRIBUTION OF VOLUNTEERS AND CONSCRIPTS

\begin{tabular}{c|c|c|c|c}
\hline Class & Volunteers & Conscripts & $\begin{array}{c}\text { Covariance } \\
\text { with Age } \\
t\end{array}$ & $\begin{array}{c}\text { Percentage } \\
\text { Volunteers }\end{array}$ \\
\hline $1 / 2$ & $67.54(28)$ & $67.91(311)$ & $1 \cdot 17$ & 8.3 \\
\hline 3 & $66.95(154)$ & $66.81(1,307)$ & 0.52 & 10.5 \\
\hline 4 & $\frac{66.47(21)}{6(3)}$ & $66.42(551)$ & 0.35 & 3.7 \\
\hline 5 & $67.01(36.56(717)$ & Not tested & 0.4 \\
\hline Total & $66.98(206)$ & $66.78(2,886)$ & Not tested * & 6.7 \\
\hline
\end{tabular}

* Totals, excluding Class $5, t=0 \cdot 74$.

The distribution of volunteers and conscripts in the social classes was examined: $\chi^{2}=90.11 ; d . f .3 ;(P<0.01)$.

The means are given in inches, and the numbers in each sample in brackets.

A $\chi^{2}$ analysis shows that there are significantly fewer volunteers in Classes 4 and 5 than would be expected on a chance basis, and correspondingly more volunteers in Classes $1 / 2$ and $3\left(\chi^{2}=90 \cdot 11\right.$, d.f. 3). The Privy Council Report on Physical Deterioration (1904) established that casual employment (which corresponds to the present Social Class 5) was the occupational background of most volunteer recruits at that time. In 1941 most volunteers belonged to Social Classes 1, 2, and 3 . This may be only a characteristic feature of war-time recruiting, but it confirms the conclusions of the Privy Council Report, that recruiting departments do not as a rule deal with a representative sample of the population.

\section{Discussion}

As observed at the beginning of this paper, the present study is the first of a series designed to show the distribution in Britain of certain anthropometric measurements that bear on the assessment of nutritional status and on the standardization of dimensions of equipment and clothing. As 
compared with peace-time, the conditions existing at the time of the survey were to a certain extent abnormal, since the civilian population had already been depleted of territorials, reserves, and many fit volunteers. It is unlikely, however, that these factors can have appreciably affected the conclusions derived from our analysis, since no significant difference in stature between volunteers and conscripts in 1941 was found, and there is no reason to suppose that any existed earlier.

It is, in fact, reasonable to suppose that our conclusions apply adequately to the whole of the Scottish working population. While our analysis dealt predominantly with men under the age of $\mathbf{4 0}$ (only 44 over that age being included), the decline in stature which occurs between the period of middle-age and retirement is so small that it can be ignored for all practical purposes. To estimate the distribution of stature of adult men in a definite area, it is necessary to take account of the distribution of stature and of the number of men in each social class in the area. For many purposes it will be safe to assume that the proportional strength of the social classes within the area is the same as in the whole population. Excluding the areas of unusual geographical variation in stature, the weighted mean stature of the "pooled national" sample in Scotland, taking account of the relative number in each social class, is $66 \cdot 79^{\prime \prime}$ (s.d. 2.61"). Where selection is likely because of social or economic factors, it will be necessary to know the body dimensions found within the occupational orders of a particular social class (e.g. skilled workers in the engineering industry are placed in Social Class 3, and the planning of machinery controls which they will use should obviously be related to the body dimensions characterizing this class; again, in the ready-made clothing industry, some materials have a limited and defined market because of price and quality.

The mean statures in the heterogeneous areas, excepting those of Paisley and Glasgow, are above average. The statistics derived from the national sample of Class $1 / 2$ will provide appropriate estimates of the distributions for all the classes in these areas.

The population covered by the medical boards of Glasgow and Paisley is large and justifies separate consideration. For these boards the mean stature of the sample of Classes 4 and 5 combined is $65 \cdot 44^{\prime \prime}$ (standard deviation 2.72) and for all the social classes combined it is $66.49^{\prime \prime}$ (standard deviation $2 \cdot 80$ ).

\section{SUMMARY}

(1) The medical records of the Ministry of Labour and National Service for the first quarter of 1941 have been sampled. Variations in stature associated with geographical region, social class, age, and occupation have been examined.

(2) The mean stature of the whole sample is $66 \cdot 82^{\prime \prime} \pm 0.04(N=3,692)$.

(3) Significant differences exist between mean statures in different social classes. Means (in inches) in Classes 1 (professional) and 5 (casual labour) were $68.93^{\prime \prime} \pm 0.37$ and $66 \cdot 44^{\prime \prime} \pm 0.10$ respectively.

(4) The mean does not increase after the 19th year, and a steady decline, which is similar for each social class, begins immediately full stature is reached.

(5) Within the same social class there is little variation in stature associated with geographical area or occupation, and no significant differences have been noted between men classified as medically fit and unfit, or between volunteers and conscripts.

We gratefully acknowledge the receipt of a grant from the Medical Research Council, and the ready assistance given to us by the Minister of Labour and National Service and by the Registrar-General. We are most grateful to Professor S. Zuckerman for many helpful discussions. We should also like to thank Dr. F. Yates for advice on the sampling, and Dr. G. M. Morant and Mr. M. J. R. Healy for much helpful advice and criticism.

\section{REFERENCES}

British Association (1884). Report of the 53rd meeting of the British Association for the Advancement of Science, 1883, p. 253.

Cathcart, E. P. Hughes, D. E. R. and Chalmers, J. G. (1935) "Physique of Man in Industry." Med. Res. Coun. Industrial Health Research Board Rep. 71. H.M.S.O., London.

Davenport, C. B., Steggerda, M., and Drager, W. (1934). Proc. Amer. Acad. Arts Sci., 69, 265.

Eckert, W. J. (1940). "Punched Card Methods in Scientific Computation." The Thomas J. Watson Astronomical Computing Bureau, Columbia University, New York.

Goring, C. (1913). "The English Convict. A Statistical Study", Table

73, p. 195. Home Office-Prisons Commission. H.M.S.O., London. Kemsley, W. F. F. (1950). Ann. Eugen., Lond., 15, 161 .

Lundborg, H., and Linders, F. J. (1926). "The Racial Characters of the Swedish Nation." Swedish State Institute for Race Biology, Uppsala. To be distributed by Almqvist and Wiksell, Uppsala; Stechert, New York and London, etc.

Martin, W. J. (1949). "Physique of Young Adult Males." M.R.C. Mem. No. 20. H.M.S.O., London.

Mem. No. 20. H.M.S.O., London.
Ministry of Labour and National Service (1947). Report for the years 1939-1946. Cmd. 7225. H.M.S.O., London.

Morant, G. M. (1950). Proc. roy. Soc. B., 137, 443.

Privy Council Committee on Physical Deterioration (1904). Abs. in Lancet, 2, 390, 557, 785.

General Register Officer (1951). "Classification of Occupations, 1950." H.M.S.O., London.

Registrar-General for Scotland (1933). Report on the Fourteenth Decennial Census of Scotland, 1931, vol. 2. H.M.S.O., Edinburgh.

Tocher, J. F. (1924). "A Record of Measurements, Weights, and other Facts relating to Man." Henderson Trust Rep., Nos. 2 and 3. Oliver and Boyd, Edinburgh. 